\title{
Pertambahan Biomasa Kepiting Bakau Scylla serrata pada Daerah Mangrove dan Tidak Bemangrove
}

\author{
Chrisna Adhi Suryono1*, Inwani', Baskoro Rochaddi2 \\ 1Departemen Ilmu Kelautan Fakultas Perika na n dan Ilmu Kela utan Universitas Diponegoro, \\ J I. Prof. Soedarto, SH. Kampus UNDIP Tembalang, Semarang 50275 \\ 2Departemen Osea nografi Fa kultas Perika nan da n Ilmu Kela utan Universitas Diponegoro, \\ JI. Prof. Soedarto, SH. Kampus UNDIP Tembalang, Semarang 50275 \\ Email: chrisna_as@yahoo.com
}

\begin{abstract}
Abstrak
Lahan mangrove mempunyai potensi dikembangkan untuk usaha penggemukan kepiting tanpa merusak, yaitu melalui konsep silvofishery. Tujuan dari penelitian ini adalah menjajaki pemeliharan kepiting bakau Scylla serrata didaerah mangrove. Metoda yang digunakan adalah eksperimen dengan rancangan acak kelompok. Perlakuan yang diterapkan adalah kepadatan yang berbeda (4 ekor/ $\left.\mathrm{m}^{2}, 6 \mathrm{ekor} / \mathrm{m}^{2} \mathrm{dan} 8 \mathrm{ekor} / \mathrm{m}^{2}\right)$ dengan kelompok (daerah mangrove dan tidak bemangrove) dengan ulangan 3 kali. Data yang diperoleh benupa penambahan biomasa dianalisa dengan balanced designs anova. Hasil yang didapat menunjukan kepiting bakau yang dipelihara didaerah mangrove memiliki penambahan biomasa yang lebih besar bila dibandingkan dengan yang dipelihara pada daerah tidak bemangrove. Kepiting bakau yang dipelihara didaerah mangrove dengan kepadatan ekor/m² pertambahan biomasanya rata rata $81,7 \mathrm{gr} / \mathrm{bulan}$; dan kepadatan 6 ekor/ $\mathrm{m}^{2}$ bertambah rata rata 77,8 gr/bulan, sedang kepadatan 8 ekor/m² 73,9 gr/bulan. Hal tersebut sangat berbeda dengan kepiting yang dipelihara pada daerah yang tidak bermangrove dimana untuk kepadatan 4 ekor/ $\mathrm{m}^{2}$ rata rata hanya bertambah 68,75 $\mathrm{gr} /$ bulan dan yang berkepadatan kepadatan $6 \mathrm{ekor} / \mathrm{m}^{2}$ bertambah rata rata 39,1 $\mathrm{gr} / \mathrm{bulan}$ sedangkan yang berkepadatan 8 ekor/m² 32,2 gr/bulan. Interaksi antara kepadatan dan lokasi (bemangrove dan bukan) memberikan pengaruh yang sangat nyata pada penambahan berat kepiting bakau $(p<0,001)$.
\end{abstract}

Kata kunci : Kepiting bakau, pertumbuhan dan mangrove

\begin{abstract}
Mangrove areas have potency as a ranch for mud crab fattening without cut down mangroves itself using silvofishery concept. The a ims of this study were to assess the possibility of mud crab cultivation on mangrove area and to find out the optimum density. Randomized block designs were applied on these studies with 3 replication. The treatment applied in this study were density of mud $\mathrm{crabs}\left(4 \mathrm{ind} / \mathrm{m}^{2}, 6\right.$ ind $/ \mathrm{m}^{2}$, and 8 ind $\left./ \mathrm{m}^{2}\right)$, and type of locations (mangrove and non-mangrove) as a block. The increasing of weigh as a result was analyzed by balanced design ANOVA. The result showed that the mud crabs cultivated in mangrove area have higher weighty increment than those cultivated in non-mangrove area. The mud crabsreared with the density $\left(4,6\right.$ and $\left.8 \mathrm{ind} / \mathrm{m}^{2}\right)$ cultivated in mangrove area have weighty increment $81.7,77.8$ and $73.9 \mathrm{gr} / \mathrm{month}$, respectively. In contras, the crabs cultivated in non-mangrove area have weighty increment $68.75 \mathrm{gr}, 39.1 \mathrm{gr}$ and $32.2 \mathrm{gr}$, respectively. Interaction between mud crab density and location types (mangrove end nonmangrove) has signific ant effect on increasing of the crabs weight ( $p \varangle 0,001)$.
\end{abstract}

Keywords: Mud crab, fattening, silvofishery and mangrove 


\section{PENDAHULUAN}

Permasalahan dalam pembesaran kepiting adalah keterbatasan lahan karena lahan tambak lebih menguntungkan digunakan untuk budidaya udang windu. Sedangkan disisi lain usaha pembesaran kepiting sudah sangat mendesak karena semakin meningkatnya permintaan pasar. Dilain pihak ketersediaan lahan hutan magrove di P. Jawa seluas $55.058 \mathrm{Ha}$, baik yang berupa hutan alami maupun hasil penghijauan (Bengen dan Adrianto, 1998). Potensi hutan mangrove tersebut dapat dimanfatkan potensinya untuk mengatasi pemasalahan budidaya kepiting tanpa merusak hutan mangrove tersebut, yaitu melalui konsep silvofishery (memelihara kepiting di daerah hutan bakau dengan karamba tanpa merusak hutan tersebut).

Kepiting bakau di Indonesia hampir didapatkan diseluruh perairan pantai terutama di daerah yang ditumbuhi hutan bakau dan pertambakan dekat pantai (Kuntiyo dkk, 1993). Kalau dilihat dari sebaran dan siklus hidup kepiting bakau, dapat dijumpai di daerah seperti estuaria, daerah hutan bakau dan pada daerah lepas pantai yang mempunyai subtrat dasar perairan berlumpur (Rattanachote dan Dangwatanakul, 1991). Hutan bakau bagi kepiting mempunyai fungsi sebagai daerah mencari makan dan perlindungan sampai hewan tersebut dewasa, sebelum kembali kepantai untuk kawin dan bertelur. Kebiasaan makan dari kepiting bakau adalah pemakan segala, pemakan bangkai dan pemakan sesama jenisnya (Prasad dkk, 1988). Dengan melihat potensi daerah mangrove yang dapat digunakan usaha pembesaran kepiting dengan syarat tanpa merusak mangrovenya. Maka penelitian penggemukan (fattening) kepiting bakau dengan model silvofishery sangat cocok dilakukan, disamping untuk mencari padat penebaran yang optimal pada tiap $\mathrm{m}^{2}$ dan lokasi yang baik (bermangrove atau tidak bemangrove) sangat tepat dilakukan dengan tujuan menjajaki penggemukan dan kepadatan yang tepat.

\section{MATER DAN METODE}

Penelitian ini dilakukan di daerah mangrove Teluk Awur Jepara tepatnya (komplek laboratorium Kelautan UNDIP) pada bulan Juli - Septembar 2000. Kepiting yang digunakan adalah kepiting hasil tangkapan nelayan di daerah setempat. Kepiting yang akan digunakan dalam penelitian adalah kepiting yang ukuran maupun beratnya relatif sama dengan berat awal rata rata 110 gram dengan kelamin betina. Sebelum penelitian dilakukan kepiting terlebih dahulu diaklimatisasikan di lokasi penelitian selama 3 hari. Masa pemeliharaan selama penelitian selama satu bulan dan jenis pakan yang diberikan berupa ikan rucah, pemberian pakan didasarkan atas prosentase berat badan. Prosentase diberikan sebanyak 5\% dari berat badan dan frekwensi pemberian sebanyak 2 kali pada pagi dan sore hari (Djunaedi dkk, 2000). Pengukuran pertambahan berat dilakukan setelah proses pemeliha ran selama sebulan.

Adapun penelitian yang dilakukan adalah penelitian ekperimen dengan disain erancangan acak kelompok. Perlakuan yang diberikan adalah jumlah kepadatan yang berbeda (4 ekor/ $\mathrm{m}^{2}, 6$ ekor/m² dan 8 ekor/ $\mathrm{m}^{2}$ ) dan kelompok yang diperlakuakan adalah lokasi (lokasi bemangrove dan tidak bemangrove) dengan ulangan 3 kali (Zar, 1996). Untuk mengetahui respon dari dua jenis faktor tersebut pada akhir penelitian kepiting ditimbang beratnya. Adapun analisa data yang berupa penambahan berat dianalisa dengan Balanced Design Anova menggunakan program statistik Minitab 10.2 .

\section{HASILDAN PEMBAHASAN}

\section{Hasil Penelitian}

Hasil penelitian terhadap pembesaran kepiting bakau S. serrata dengan kepadatan berbeda yang dipelihara di daerah bemangrove dan tidak bemangrove menunjukan hasil pada Gambar 1. 


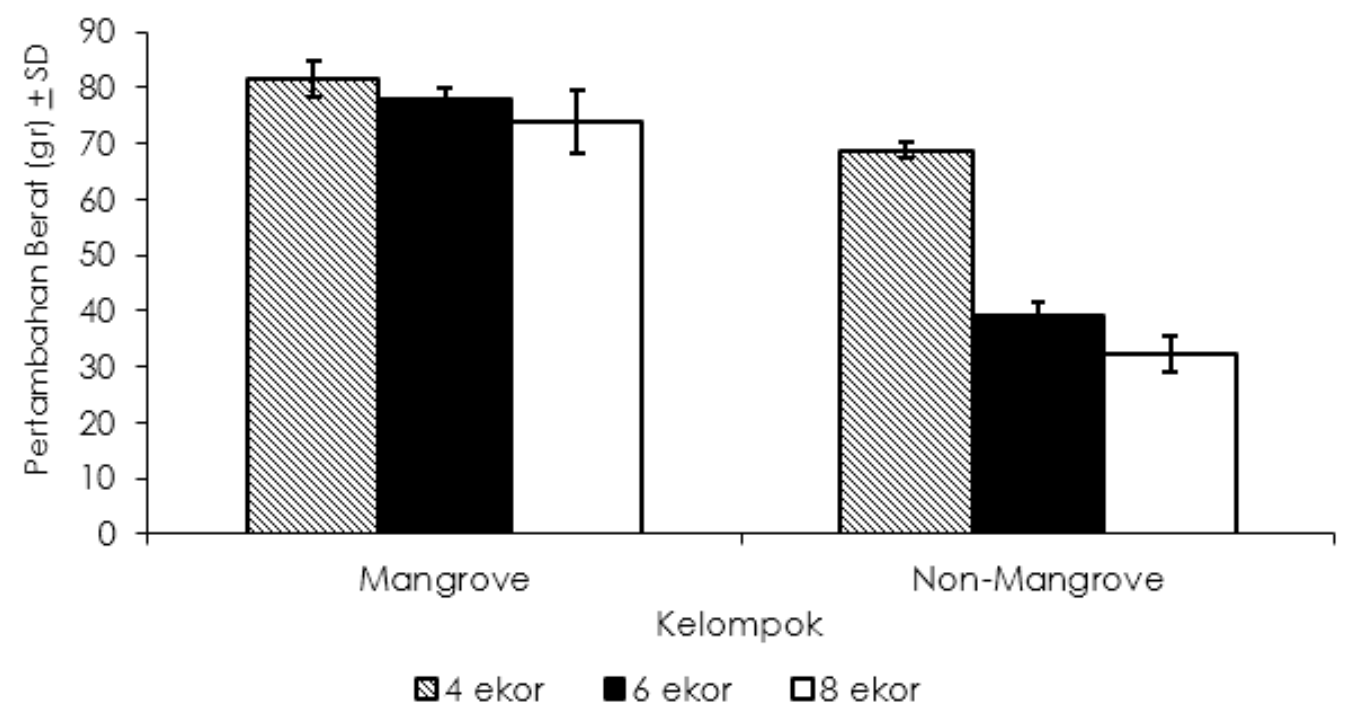

Gambar 1. Grafik pertambahan berat S.serrata pada kelompok berbeda dan kepadatan berbeda.

Tabel 1. Balanced Designs ANOVA antara kelompok (mangrove) dan Kepadatan S.serata terhadap penambahan berat S. Serrata

\begin{tabular}{llrrrr}
\hline \multicolumn{1}{c}{ Source } & DF & \multicolumn{1}{c}{ SS } & \multicolumn{1}{c}{ MS } & \multicolumn{1}{c}{ F } & \multicolumn{1}{c}{ P } \\
\hline Kepadatan & 2 & 1604.4 & 802.2 & 583.96 & 0.000 \\
Mangrove & 1 & 4360.7 & 4360.7 & 3174.34 & 0.000 \\
Kepadatan*Mangrove & 2 & 753.2 & 376.6 & 274.15 & 0.000 \\
Error & 12 & 16.5 & 1.4 & & \\
Total & 17 & 6734.9 & & & \\
\hline
\end{tabular}

Penambahan berat tertinggi terlihat pada kepiting yang dipelihara selama satu bulan pada daerah mangrove, untuk kepadatan 4 ekor/m² dengan pertambahan berat rata rata $81,7 \mathrm{gr}, 6$ ekor/ $\mathrm{m}^{2}$ dengan pertambahan berat rata rata $77,8 \mathrm{gr}$ dan untuk kepadatan 8 ekor/m² dengan pertambahan berat rata rata 73.9 gr. Sedangkan untuk untuk kepiting yang dipelihara pada daerah yang tidak bermangrove terlihat penambahan berat rata ratnya lebih rendah bila dibandingkan dengan kepiting yang dipelihara pada daerah bermangrove, hanya keterkecualian terlihat pada kepiting yang dipelihara dengan kepadatan 4 ekor $/ \mathrm{m}^{2}$ penambahan beratnya rata rata $68,75 \mathrm{gr}$. penambahan berat rata-rata pada kepadatan 6 ekor/m² sebesar $39,1 g r$ dan 8 ekor/ $\mathrm{m}^{2}$ sebesar $32.2 \mathrm{gr}$.
Hasil analisa balanced anova terlihat bahwa kepadatan S. serrata yang berbeda pada kedua kelompok (mangrove dan non-mangrove) menunjukanan perbedaan yang sangat nyata ( $p<0.001$ ), demikian juga pengaruh yang diberikan oleh kelompok terhadap penambahan berat menunjukan perbedan yang sangat nyata $(p<0,001)$. Lebih lanjut interaksi antara kepadatan yang berbeda dan tipe lokasi juga memperlihatkan perbedaan yang sangat nyata terhadap pertambahan berat $\mathrm{S}$. serrata $\quad(p<0,001)$. Hasil tersebut menunjukan bahwa perlakuan yang diberikan (kepadatan yang berbeda dan tipe lokasi) memberikan pengaruh terhadap penambahan berat kepiting bakau yang dipelihara dalam waktu 1 bulan. 


\section{Pembahasan}

Hasil penelitian menunjuka an bahwa kepiting yang dipelihara di daerah bermangrove memiliki pertumbuhan yang lebih besar bila dibandingkan dengan yang dipelihara di lokasi perairan tanpa mangrove, hal ini membuktikan bahwa mangrove memberi sesuatu yang positif terhadap kehidupan S. serrata baik itu makanan ataupun kenyamanan hidup. Beberapa informasi terdahulu mengatakan $S$. serrata mempunyai habitat di daerah pantai, estuaria dan daerah hutan mangrove yang berair payau yang bersubtrat lumpur (Rattanachote. and Dangwatanakul. 1991). Infomasi tersebut menunjukan bahwa daerah mangrove daerah yang cocok untuk hidup $S$. serrata disamping mampu memberi perlindung, karana selama pengamatan dalam penelitian biasanya $S$. serrata tersebut menyembunyikan diri diantara akar mangrove atau membenamkan diri dalam lumpur yang banyak serasah daun mangrovenya. Dengan demikian satu kondisi pemenliharaan $S$. serrata didapatkan. Kecocokan kepiting tersebut cocok hidup di daerah mangrove juga telah dila porkan oleh Ario, dkk (1999) yang mengatakan S. serrata betina dewasa denga $\mathrm{n}$ berat minimal $100 \mathrm{gr}$ telah bertelur setelah dipelihara selama dua minggu dengan sistem silvofishery. Lebih lanjut Suryono, dkk (1999) menginformasikan S. serrata yang dipelihara dalam karamba dalam ingasi tambak akan bertelur setelah dipelihara minimal 21 hari. Informasi tersebut tentunya memperkuat dugaan $\mathrm{S}$. serrata memang cocok untuk dipelihara didaerah bemangrove.

Pertambahan berat yang lebih besar S. semata yang dipelihara di daerah mangrove diduga juga karena kepiting memanfaatkan makanan alami yang ada didaerah mangrove tersebut disamping memakan makanan yang diberikan. Namun seberapa besar sumber pakan alami yang ada dilokasi penelitian tidak diketahui. Kepiting mempunyai kebiasaan makanan selain camivour juga temasuk omnivour, juga scavenger dan pemakan jenis (Prasad dkk, 1988). Dari informasi tersebut dapat dipahami, kemungkinan kepiting yang dipelihara didaerah mangrove juga memanfaatkan organisme bentik ataupun detritus yang berasal dari daun mangrove bila hal tersebut dilihat kepiting sebagai pemakan segala (omnivour). Lebih lanjut Fatima (1991) mengatakan bahwa kepiting bakau merupakan binatang noktumal yaitu binatang yang lebih aktif mencari makan pada malam hari, dan kebiasaan makan kepiting bakau menjelang pagi dan malam hari. Melihat kebiasan waktu makan yang menjelang pagi atau malam bila dikaitkan dengan pemberian pakan selama penelitian pada waktu pagi maupun sore hari, kemungkinan pakan yang diberikan akan dimakan menjelang malam. Sedangkan menjelang pagi kemungkinan kepiting makan pakan a lami yang ada diperairan mangrove.

Budidaya kepiting bakau dapat dilakukan dalam berbagai cara antara lain dengan menggunakan lokasi tambak, karamba bambu atau dengan kolam. Usaha budidaya ini biasanya merupakan usaha penggemukan yang waktunya relatip singkat. Usaha pembesaran kepiting bakau dengan menggunakan karamba bambu dilakukan untuk mencapai kepiting bertelur (Ladra, 1991). Usaha pembesaran ini biasanya dilakukan pada perairan terbuka, atau menurut Arifin (1993) lahan yang dapat digunakan uuntuk membudidayakan kepiting bertelur ada lah saluran ingasi, tambak dan daerah dipinggir sungai, kesemua lahan tersebut harus mempunyai air yang mencukupi. Dilihat dari fungsi hutan mangrove yang menupakan habitat alami kepiting bakau maka sangat tepat daerah tersebut dijadikan daerah pembesaran atau penggemukan dengan konsep silvofishery yaitu dengan cara tumpang sari antara mangrove dan kepiting tanpa merusak mangrove itu sendin. Hal tersebut telah dibuktikan oleh Ario, dkk (1999) dimana kepiting bakau lebih cepat tumbuh dan bertelur bila dipelihara tumpang sari dengan mangrove (silvofishery). Hal tersebut juga telah dibuktikan dalam penelitian yang telah dilakukan dan terbukti bahwa pembesaran kepiting dengan konsep silvofishery lebih baik bila 
dibandingkan dengan cara karamba biasa.

\section{KESIMPULAN}

Dari hasil penelitian dapat disimpulkan bahwa daerah mangrove sangat cocok untuk pembesaran kepting bakau. Kepadatan yang terbaik adalah antara 4 ekor/m², namun kepadatan 6 - 8 ekor/ $\mathrm{m}^{2}$ masih baik bila dibandingkan dengan yang dipelihara diluar daerah mangrove

\section{DAFTAR PUSTAKA}

Arifin, S. 1993. Budidaya kepiting bakau dengan keramba apung. Techner.08 Th II. Dinas Perikanan Gresik. Jawa Timur.

Ario, R, Suryono, C.A dan Suryono. 1999. Pengenalan dan pelatihan sistem "Silvofishery" dalam upaya pemberdayaan masyarakat pelestari hutan mangrove di Desa Pasar Banggi Kecamatan Rembang, Kabupaten Rembang. Laporan Pengabdian Masyarakat. Tidak Dipublikasikan. Lembaga Pengabdian Masyarakat. UNDIP. Semarang

Bengen, D. E. dan Andrianto, L. 1998. Strategi pemberdayaan masyarakat dalam pelestarian hutan mangrove. dalam Lokakarya Jaringan Kerja Pelestarian Mangrove, Pemalang 12 13 Agustus 1998.

Djunaedi, A,. Subandiyono, Sa rito dan Gunawan, W. S. 2000. Pertumbuhan kpiting bakau Scylla serrata pada budidaya dengan kepadatan dan jenis yang berbeda. Ilmu Kelautan, $\mathrm{V}(17)$ : $62-65$.

Fatima, H. 1991. Kepiting hidup pilihan pelanggan di Malaysia. Warta Aquakultur, 1 (1) Edisi J uli/September. Jakarta.

Kuntiyo., Arifin, Z dan Supratno, T.K.P. 1993. Pedoman budidaya kepiting bakau (Scylla serrata) di tambak. BBAP. Jepara.

Landra, F.D, 1991. Mud crab fattening practises in the Philippines. The Bureau of Fisheries and Aquatic Resources. Philippines.

Prassad, P.N., Sudharshana, R. and Neelakatan, B. 1988. Feeding ecology of mud crab (Scylla serrata) from Sankari Brackhiswater. J. Bombay Not. Hist. Soc, 85 (1): 79 - 89.

Rattanachote, A. and Dangwatanakul, R. 1991. Mud crab (Scylla seratta) fattenning in SuratThani Province. The Surat Thani coastal aquaculture development centre, Kanchanadict. Surat Thani Province. Tha iland.

Suryono, Imwani dan Suryono, C.A. 1999. Pendayagunaan tambak bero dan saluran ingasi untuk budidaya penggemukan kepiting bakau Scylla serrata dengan sistem karamba guna meningkatkan pendapatan nelayan di Kecamatan Sayung, Kabupaten Demak. Laporan Pengabdian Masyarakat. Tidak Dipublikasikan. Lembaga Pengabdian Masyarakat. UNDIP. Sema rang

Zar, J. E. 1996. Biostatistical analysis. Prentice Hall, New J a ersey. 662 p 